\section{(2) OPEN ACCESS}

\title{
Thromboprophylaxis in lower limb immobilisation after injury (TiLLI)
}

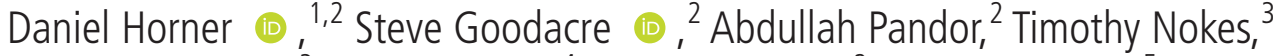 \\ Jonathan Keenan, ${ }^{3}$ Beverley Hunt, ${ }^{4}$ Sarah Davis $\odot{ }^{2}{ }^{2}$ John W Stevens, ${ }^{5}$ Kerstin Hogg ${ }^{6}$
}

\begin{abstract}
Additional material is published online only. To view, please visit the journal online (http://dx.doi.org/10.1136/ emermed-2019-208944).

${ }^{1}$ Emergency Department, Salford Royal Hospitals NHS Trust, Salford, UK

${ }^{2}$ Centre for Urgent and Emergency Care Research (CURE), University of Sheffield, Sheffield, UK

${ }^{3}$ Departments of Haematology and Trauma/Orthopaedics, Plymouth Hospitals NHS Trust, Plymouth, UK

${ }^{4}$ Departments of Haematology and Rheumatology, Guy's \& St Thomas's NHS Foundation Trust, London, UK

${ }^{5}$ Department of Health

Economics and Decision Science, SCHARR, University of Sheffield, Sheffield, UK

${ }^{6}$ Department of Medicine, McMaster University, Hamilton, Ontario, Canada
\end{abstract}

Correspondence to

Dr Daniel Horner, Salford Royal Hospitals NHS Trust, Salford M6 8HD, UK; danielhorner@nhs.net

Received 17 July 2019 Revised 10 October 2019 Accepted 17 October 2019 Published Online First 6 November 2019

\section{Check for updates}

(C) Author(s) (or their employer(s)) 2020. Re-use permitted under CC BY-NC. No commercial re-use. See rights and permissions. Published by BMJ.

To cite: Horner $\mathrm{D}$

Goodacre S, Pandor A,

et al. Emerg Med $\mathrm{A}$

2020;37:36-41.

\section{ABSTRACT}

Venous thromboembolic disease is a major global cause of morbidity and mortality. An estimated 10 million episodes are diagnosed yearly; over half of these episodes are provoked by hospital admission/procedures and result in significant loss of disability adjusted life years. Temporary lower limb immobilisation after injury is a significant contributor to the overall burden of venous thromboembolism (VTE). Existing evidence suggests that pharmacological prophylaxis could reduce overall VTE event rates in these patients, but the proportional reduction of symptomatic events remains unclear. Recent studies have used different pharmacological agents, dosing regimens and outcome measures. Consequently, there is wide variation in thromboprophylaxis strategies, and international guidelines continue to offer conflicting advice for clinicians. In this review, we provide a summary of recent evidence assessing both the clinical and cost effectiveness of thromboprophylaxis in patients with temporary immobilisation after injury. We also examine the evidence supporting stratified thromboprophylaxis and the validity of widely used risk assessment methods.

\section{CASE 1}

A 60-year-old woman attends your department after a fall downstairs, injuring her right ankle. X-rays confirm a Weber B fracture to the lateral malleolus without talar shift. There is no pain to the medial aspect. The orthopaedic plan is for below-knee plaster immobilisation in a non-weight-bearing cast, conservative management and outpatient review in 7-10 days' time. On further assessment, a body mass index (BMI) of 35 is apparent, along with a history of chronic obstructive pulmonary disease.

\section{CASE 2}

A 25 -year-old man attends your department after a crush injury to his left foot sustained at work. X-rays reveal undisplaced fourth and fifth metatarsal neck fractures. The orthopaedic team advise a walking boot and to allow partial weight bearing as tolerated until outpatient review later that week. On further assessment, the patient has no other medical history and no family history of venous thromboembolism (VTE). He takes no medications. Despite analgesia in the department, he remains unable to put any weight through the affected limb.

\section{QUESTION}

Should these patients be offered thromboprophylaxis to reduce their short-term risk of VTE?
To answer that question, we will provide a short summary of the problem, followed by a review of the evidence and a practical guide to decisionmaking and intervention in these clinical scenarios.

\section{BACKGROUND}

VTE is a significant global health burden, with incident events alone costing the UK an estimated $£ 640$ million and the USA an estimated \$7-10 billion each year. ${ }^{12}$ Within the last decade, VTE has resulted in more deaths than prostate cancer, breast cancer, road traffic accidents and AIDS combined. ${ }^{3}$

Temporary immobilisation after injury accounts for approximately $2 \%$ of all VTE cases in registry data. ${ }^{4}$ These cases are potentially preventable with early pharmacological thromboprophylaxis. However, it is unclear which patients will benefit from such intervention, which will be harmed, whether clinical outcomes are improved as a result of treatment and whether prophylaxis is costeffective. As a result, international guidelines continue to recommend different management options; the UK advises routine assessment and individualised prescribing, for example, whereas US guidelines advise against thromboprophylaxis in this population. ${ }^{56}$

This issue was recently highlighted as a research priority for emergency medicine, through the James Lind Alliance Priority Setting Partnership in the UK. ${ }^{7}$ While the debate continues, case report data and media coverage continue to highlight recurrent and tragic outcomes. ${ }^{89}$ It remains unclear whether these tragedies were avoidable. In many regions, legal rulings and recommendations by the coroner/medical examiner delivered with the aim of avoiding future deaths have forced the clinical agenda without recourse to scientific evidence. ${ }^{10}$ Practice remains variable with differing levels of engagement and awareness, despite the relative frequency of the problem. It is imperative that a cross-specialty consensus is reached on management of VTE risk, to ensure that clinicians and patients can be adequately informed and counselled on the merits of intervention.

This article summarises recent work on this topic and provides pragmatic guidance and decision support for clinicians.

\section{What is the risk of VTE following lower limb} injury and temporary immobilisation?

A recent Cochrane review on this topic suggests wide variation in the incidence of VTE following lower 
limb immobilisation without thromboprophylaxis, reporting a range between $4.3 \%$ and $40.0 \%$ within the literature. ${ }^{11}$ These figures are based on the outcome of 'any VTE', including routine screening and detection of isolated distal deep vein thrombosis (DVT). There is ongoing debate regarding the clinical relevance of such a composite endpoint and the sensitivity of the contributing diagnostics. ${ }^{12-14}$ Of more importance to clinicians and patients is the incidence of morbidity after immobilisation. This is more challenging to define but suggested by many to be the incidence of only clinically relevant or symptomatic VTE, warranting repeat hospital attendance and/or intervention. ${ }^{15}$ Accurate estimates of this endpoint suffer from limitations in the injured population regarding subjectivity. When should a clinician or patient suspect VTE in a leg that is painful and swollen at baseline from injury? However, recent studies with transparent reporting of clinically relevant outcomes demonstrate a high level of consistency. The recent Cochrane review extracted data from six studies ${ }^{16-21}$ involving just under 3000 randomised patients; symptomatic VTE occurred in 1.8\%-5.5\% of conservatively managed patients. These results suggest that without thromboprophylaxis, approximately 1 in every 50 patients will suffer a symptomatic VTE event (including symptomatic distal and proximal DVT and pulmonary embolism (PE)) following temporary immobilisation after injury. This is likely to be an underestimate given the range previously mentioned, the exclusion of high-risk patients from trial design and the general health equity of patients willing to engage with research.

\section{Is thromboprophylaxis clinically effective?}

Can pharmacological thromboprophylaxis reduce this morbidity burden and, if so, by what margin? We performed a recently updated systematic review and network meta-analysis to compare any pharmacological intervention against control for this defined population. ${ }^{22}{ }^{23}$ This review included the Prevention of Thrombosis after Lower Leg Plaster Cast (POT-CAST) trial, ${ }^{21}$ which has reignited debate on this important topic, and other recent randomised studies assessing the novel use of fondaparinux for this indication. We identified 13 trials with 6857 patients suitable for inclusion. ${ }^{16-21} 24-30$ Interventions included prophylactic dose low molecular weight heparin (LMWH) or fondaparinux only. We examined four additional trials that had been excluded from the previous Cochrane review and one trial published subsequently. We found no trial evidence examining the use of direct oral anticoagulants (DOACs) in this situation. Risk of bias was present in all included studies. We found that both LMWH and fondaparinux significantly reduced the odds of clinically detected DVT, PE and any VTE. Intervention appeared to halve the risk of VTE across all classifications. ${ }^{23}$

It follows that the absolute $2 \%$ risk of clinically significant VTE following temporary immobilisation after injury can be effectively halved to $1 \%$ with prophylactic dose anticoagulation. Although this may represent a potentially high number needed to treat, this value would depend primarily on baseline risk (which is likely to vary within the population) and also would be considered in the context of prevalence. Approximately 70000 patients are immobilised and discharged from EDs in the UK alone every year. ${ }^{23}$ Even a $1 \%$ absolute risk reduction in the VTE event rate in this cohort would therefore represent prevention of 700 clinically relevant VTE events. Assuming these events would be detected and treated as provoked VTE in the absence of thromboprophylaxis, they would incur 63000 patient days of therapeutic dose anticoagulation, with accompanying costs and harms.

\section{What are the harms of thromboprophylaxis?}

Clear definitions are now in place for the identification and classification of bleeding events in trials of anticoagulation and thromboprophylaxis. ${ }^{31-33}$ Using these, our above systematic review found limited evidence of harm from prophylactic dose anticoagulation in this population. Only four major bleeding events were identified in total, with insufficient evidence of an increase within the LMWH group (OR 1.45, 95\% CrI 0.08 to 32.17). Although these results are inconclusive given the low frequency of events, only four events within a trial sample of just under 7000 patients provide some reassurance on safety.

Minor bleeding as a secondary outcome varied across the population, being found in $0 \%-10.5 \%$ of patients treated with LMWH, in $0 \%-1.5 \%$ of patients treated with fondaparinux and in $0 \%-6.8 \%$ of the control groups. No cases of death attributable to VTE or intervention were identified within the study, and in those trials monitoring for the incidence of heparin-induced thrombocytopenia (HIT), no cases were detected. The most common adverse event of infection appeared equal between control and intervention groups when strictly defined. ${ }^{21}$

\section{Do the benefits of thromboprophylaxis justify the risks?}

Thromboprophylaxis reduces the risk of thromboembolism but may increase the risk of bleeding. Our data were inconclusive on this latter aspect, but it remains one of the primary clinical concerns regarding the use of thromboprophylaxis. We undertook decision-analytic modelling to determine how these risks might compare in people undergoing lower limb immobilisation due to injury. ${ }^{34}$ Table 1 summarises the results. The risk of fatal PE (which often drives decisions and recommendations regarding thromboprophylaxis) is very small, and the reduction in this risk associated with thromboprophylaxis is roughly matched by an increase in the risk of fatal bleeding or non-fatal intracranial haemorrhage. Overall, the risk of death or non-fatal intracranial haemorrhage is about 1 in 4000 , whether thromboprophylaxis is

Table 1 Predicted clinical outcomes per 100000 patients with lower limb immobilisation due to injury Outcomes at 6 months per 100000 patients Outcomes at 5 years per 100000 patients

\begin{tabular}{|c|c|c|c|c|c|c|c|c|c|c|c|c|}
\hline & & \\
\hline & $\begin{array}{l}\text { Fatal } \\
\text { PE }\end{array}$ & $\begin{array}{l}\text { Fatal } \\
\text { bleed }\end{array}$ & $\begin{array}{l}\text { Non-fatal } \\
\text { ICH }\end{array}$ & $\begin{array}{l}\text { Other } \\
\text { major } \\
\text { bleed }^{*}\end{array}$ & $\begin{array}{l}\text { Non-fatal } \\
\text { PE }\end{array}$ & $\begin{array}{l}\text { Symptomatic } \\
\text { DVT }\end{array}$ & $\begin{array}{l}\text { Asymptomatic } \\
\text { DVT }\end{array}$ & PTS & $\begin{array}{l}\text { PE } \\
\text { survivor } \\
\text { with } \\
\text { CTEPH }\end{array}$ & $\begin{array}{l}\text { PE } \\
\text { survivor } \\
\text { without } \\
\text { CTEPH }\end{array}$ & $\begin{array}{l}\text { ICH } \\
\text { survivor }\end{array}$ & $\begin{array}{l}\text { Dead } \\
\text { (any } \\
\text { cause) }\end{array}$ \\
\hline $\begin{array}{l}\text { No } \\
\text { prophylaxis }\end{array}$ & 12 & 9 & 5 & 26 & 415 & 907 & 7052 & 1859 & 11 & 397 & 5 & 1133 \\
\hline Prophylaxis & 7 & 12 & 8 & 35 & 225 & 492 & 3820 & 1007 & 6 & 215 & 7 & 1129 \\
\hline
\end{tabular}

*Patients having other major bleeds could also have a DVT or non-fatal PE.

CTEPH, chronic thromboembolic pulmonary hypertension; DVT, deep vein thrombosis; ICH, intracranial haemorrhage; PE, pulmonary embolism; PTS, post-thrombotic syndrome. 
given or not. These are tragic events and, given the large population undergoing immobilisation, will occur with some frequency. However, our analysis suggests that thromboprophylaxis will not markedly change their incidence.

The main benefits of thromboprophylaxis lie in preventing non-fatal PE, symptomatic DVT and, in particular, asymptomatic DVT. Benefits for patients are assumed to accrue in the form of reduced long-term complications, particularly post-thrombotic syndrome. We estimated that, taking all effects into account, thromboprophylaxis results in 0.015 additional quality-adjusted life years (QALYs) per patient treated $(95 \%$ credible interval (CrI 0.004 to 0.029 ), indicating an overall benefit. However, it is uncertain whether a reduced risk of asymptomatic DVT leads to a reduced risk of post-thrombotic syndrome, so this finding should be treated with some caution. ${ }^{35}$

\section{Is thromboprophylaxis cost-effective?}

Given the cost implications of prophylaxis, the low absolute event rate and the potential implications of any recommendations it is necessary to examine the cost effectiveness of this intervention. Our recent work for the Health Technology Assessment Programme examined this in detail. ${ }^{23}$ We examined the wider literature to generate estimates of incidence for VTE, post-thrombotic syndrome, chronic thromboembolic pulmonary hypertension, intracranial haemorrhage, major bleeding and death among other potential outcomes. We subsequently assigned costs to these outcomes then designed a decision tree and used a Markov model to generate estimates of overall cost effectiveness.

Based on the mean costs and QALYs gained, we found an incremental cost-effectiveness ratio (ICER) for thromboprophylaxis compared with no thromboprophylaxis of $£ 13524$. Based on standard thresholds used by the National Institute for Health and Care Excellence (NICE) in England, this value would fall below the ICER threshold of $£ 20000$ and, as such, the intervention would broadly be considered as cost-effective.

We went on to examine the potential cost effectiveness of using a risk assessment method (RAM) to recommend stratified thromboprophylaxis. Several published RAMs were available with threshold prognostic accuracy data, to inform the modelling. ${ }^{36} 37$ We found that a RAM could potentially improve the cost effectiveness of thromboprophylaxis, depending on the threshold score at which thromboprophylaxis would be given. The optimal threshold, assuming the RAM operated with diagnostic characteristics similar to the Leiden Thrombosis Risk in Plaster (cast) (L-TRiP(cast)) score, would result in a sensitivity of $84 \%-89 \%$ and a specificity of $46 \%-55 \%$ for predicting VTE.
Can we safely risk stratify patients to maximise clinical and cost effectiveness?

Using risk factors to tailor thromboprophylaxis recommendations is a common strategy in hospitals. ${ }^{38}$ There is face validity to the concept of risk prediction and tailored therapy in temporary lower limb immobilisation, which is strengthened by the low absolute risk and costs/inconvenience of treatment. ${ }^{15}$

We examined the literature to try and identify whether established individual VTE risk factors can predict the likelihood of subsequent disease in this ambulatory cohort of patients. A further systematic review was conducted, identifying 15 studies and 80678 patients for inclusion. Meta-analysis of data was not possible due to significant variation between studies regarding data collection methods. All studies were deemed to be at moderate to severe risk of bias. We found advancing age and injury pattern to be consistently associated with increased VTE risk. BMI was the third most consistent individual risk highlighted, although overall results were conflicting. A total of 12 other risk factors analysed did not demonstrate any consistency in association with VTE across the dataset. ${ }^{39}$ A subsequent publication supports our findings, reporting injury pattern, family history and BMI to be the individual risk factors most associated with VTE risk, among the POT CAST trial cohort. ${ }^{40}$

We conducted a further systematic review and engaged topic experts to try and identify available RAMs for use in this population. This work identified seven RAMs, three of which have undergone attempted external validation. ${ }^{36} 41-46$ Variation and essential characteristics of the identified RAMs are presented in table 2. All studies looking to derive or externally validate a RAM were deemed to be at high risk of bias and did not report discrimination or calibration within an appropriate external population.

Prognostic accuracy measures for the three scores evaluated in two validation studies are presented in table 3. RAM sensitivity varies from $57.1 \%$ to $92.6 \%$ and specificity varies from $4.76 \%$ to $60.8 \%$. As an ordinal score with additional validation data, The L-TRiP(cast) RAM is displayed in this table using thresholds denoting optimal performance and to allow direct comparison with other validated scores. The area under the receiver operating characteristic curve for the L-TRiP(cast) score ranged from 0.77 (95\% CI 0.66 to 0.87 ) in the derivation cohort to 0.77 (95\% CI 0.58 to 0.96 ) and 0.95 (95\% CI 0.91 to 0.99 ) in the two subsequent validation cohorts. In addition, subsequent retrospective evaluation of the $\mathrm{L}-\mathrm{TRiP}$ (cast) score within the POT-CAST cohort reports a lower area under the curve value of $0.69(95 \%$ CI $0.58,0.80) .{ }^{40}$ As such, although the concept of a RAM is intuitive in this situation, the available supporting

Table 2 Summary of design characteristics and threshold levels of identified RAMs

\begin{tabular}{|c|c|c|c|c|c|c|c|}
\hline Risk assessment model & Acronym/descriptor & Derivation & Design & $\begin{array}{l}\text { Incorporation of } \\
\text { bleeding risk? }\end{array}$ & $\begin{array}{l}\text { Number of } \\
\text { variables }\end{array}$ & $\begin{array}{l}\text { Threshold } \\
\text { (suggested } \\
\text { cut-point) }\end{array}$ & $\begin{array}{l}\text { Attempted } \\
\text { validation? }\end{array}$ \\
\hline Roberts et $\left.a\right|^{42}$ & The GEMNet guideline & EC & Dichotomous & Yes & 11 & N/A & Yes \\
\hline Keenan et a $\left.\right|^{49}$ & The Plymouth Rule & EC & Ordinal & No & 14 & $>2$ & Yes \\
\hline Nemeth et $a l^{36}$ & The L-TRiP(cast) score & Regression & Ordinal & No & 14 & $>8$ & Yes \\
\hline Saragas et al ${ }^{41}$ & The modified Caprini score & $\mathrm{EC}$ & Ordinal & No & 36 & $>1$ & No \\
\hline Eingartner et $a l^{45}$ & $\mathrm{~N} / \mathrm{A}$ & $\mathrm{EC}$ & Ordinal & No & 9 & $>1$ & No \\
\hline Haque et $a l^{46}$ & $\mathrm{~N} / \mathrm{A}$ & $\mathrm{EC}$ & Ordinal & No & 14 & $>2$ & No \\
\hline Giannadakis et a/ $/^{44}$ & $\mathrm{~N} / \mathrm{A}$ & EC & Dichotomous & No & 12 & N/A & No \\
\hline
\end{tabular}

EC, Expert Consensus; GEMNet, Guidelines in Emergency Medicine Network; L-TRIP(cast), Leiden Thrombosis Risk in Plaster (cast); N/A, not applicable; RAM, risk assessment method. 
Table 3 Diagnostic performance of the L-TRiP(cast), GEMNet and Plymouth risk assessment models

\begin{tabular}{|c|c|c|c|c|}
\hline Author & Roberts et al & Keenan et al & Nemeth et al & \\
\hline Risk assessment model & GEMNet & Plymouth & $\begin{array}{l}\text { L-TRiP(cast) } \\
\text { with a } \\
\text { cut-point of } 8 \\
\text { or above }\end{array}$ & $\begin{array}{l}\text { L-TRiP(cast) } \\
\text { with a } \\
\text { cut-point of } 9 \\
\text { or above }\end{array}$ \\
\hline Sensitivity $(95 \% \mathrm{Cl})$ & $\begin{array}{l}85.7 \% \\
(62.6 \% \text { to } 96.2 \%)\end{array}$ & $\begin{array}{l}57.1 \% \\
(33.4 \% \text { to } 77.4 \%)\end{array}$ & $92.6 \%$ & $80.8 \%$ \\
\hline Specificity $(95 \% \mathrm{Cl})$ & $\begin{array}{l}4.76 \% \\
(0.2 \% \text { to } 25.9 \%)\end{array}$ & $\begin{array}{l}52.4 \% \\
\text { (30.3\% to } 73.6 \%)\end{array}$ & $39.7 \%$ & $60.8 \%$ \\
\hline $\begin{array}{l}\text { Positive predictive value } \\
(95 \% \mathrm{Cl})\end{array}$ & $\begin{array}{l}47.4 \% \\
(31.3 \% \text { to } 64.0 \%)\end{array}$ & $\begin{array}{l}54.5 \% \\
(32.7 \% \text { to } 74.9 \%)\end{array}$ & $3.8 \%$ & $5.0 \%$ \\
\hline $\begin{array}{l}\text { Negative predictive value } \\
(95 \% \mathrm{Cl})\end{array}$ & $\begin{array}{l}25.0 \% \\
(1.3 \% \text { to } 78.1 \%)\end{array}$ & $\begin{array}{l}55.0 \% \\
(32.0 \% \text { to } 76.2 \%)\end{array}$ & $99.5 \%$ & $99.2 \%$ \\
\hline $\begin{array}{l}\text { Likelihood ratio positive } \\
(95 \% \mathrm{Cl})\end{array}$ & $\begin{array}{l}0.90 \\
\text { (0.73 to } 1.10)\end{array}$ & $\begin{array}{l}1.20 \\
\text { (0.67 to } 2.15)\end{array}$ & 1.5 & 2.1 \\
\hline $\begin{array}{l}\text { Likelihood ratio negative } \\
(95 \% \mathrm{Cl})\end{array}$ & $\begin{array}{l}3.00 \\
(0.16 \text { to } 55.31)\end{array}$ & $\begin{array}{l}0.81 \\
(0.46 \text { to } 1.46)\end{array}$ & 0.2 & 0.3 \\
\hline $\begin{array}{l}\text { Proportion receiving } \\
\text { thromboprophylaxis } \\
(95 \% \mathrm{Cl})\end{array}$ & $\begin{array}{l}90.5 \% \\
\text { (76.5\% to } 96.9 \%)\end{array}$ & $\begin{array}{l}52.4 \% \\
\text { (36.6\% to } 67.7 \% \text { ) }\end{array}$ & $87.8 \%$ & $74.7 \%$ \\
\hline
\end{tabular}

evidence is weak. Further RAMs (such as the Trauma, Immobilisation and Patients' Characteristics (TIP) score) continue to be published using Delphi consensus methodology and other derivation techniques, reporting improved performance metrics on internal validation. ${ }^{47}$ All proposed RAMS remain in need of robust external validation.

\section{What are the key uncertainties and challenges moving forward?}

Can I use a DOAC for this indication?

There is no trial evidence examining the use of DOAC medications in this clinical scenario. As such, there are no available data on the clinical or cost effectiveness of these drugs. Any such use would be off licence and approved as part of a trust protocol using local pharmacy and thrombosis committee governance structures.

Many trusts have taken this option and are starting to publish prospective datasets recording their experience. ${ }^{1048}$ Evaluation of this strategy with organisational support and careful oversight is to be encouraged and will provide estimates of effectiveness and safety that may support the case for future research.

\section{Does this evidence apply to temporary splints as well as plaster} casts?

The majority of research in this area focusses on immobilisation in plaster. As such, all estimates of effectiveness are not necessarily generalisable to other forms of immobilisation, which may allow partial weight bearing or less restriction in mobility. However, a caution should be noted here; often patients are treated with advice to partially weight bear when they clearly cannot do so. These patients remain at risk of VTE through immobility. NICE guideline NG89 currently defines lower limb immobilisation as 'any clinical decision taken to manage the affected limb in a way that would prevent normal weight-bearing status, or use of that limb, or both'. Many patients who are managed with crutches and a splint would meet this definition and therefore justify risk assessment. This does not mandate prophylaxis but does recommend consideration of risk and shared decision-making (SDM).

\section{Which RAM is best?}

The evidence provided earlier highlights the lack of external validation data for any RAM. The Guidelines in Emergency Medicine Network (GEMNet), Plymouth rule, L-TRiP(cast) and
TIP score all appear to have limited supporting/validation data and variable strengths and weaknesses. ${ }^{3642474}$ If using a RAM, clinicians should focus on consistency and serial audit to ensure appropriate use of the RAM, proportional use of thromboprophylaxis, patient outcomes and national benchmarking. For transparency and comparison, an example score sheet for each of the four RAMs previously mentioned can be found in online supplementary figures S1-S4.

\section{Do these patients need blood tests prior to commencement of LMWH?}

National guidelines from the British Committee for Standards in Haematology $(\mathrm{BCSH})$ are clear that any patient receiving any form of heparin should have an estimate of baseline renal function and platelet count recorded. ${ }^{50}$ These tests have a clear rationale: ensuring appropriate dosing and agent choice, absence of coagulopathy and recording baseline platelet count to clarify the degree of any future drop. These tests are equally necessary prior to commencement on any DOAC agent. The same BCSH guidance clarifies that adverse events such as HIT are rare enough with prophylactic dose LMWH that further routine platelet counts are unnecessary, and repeat testing should be based only on clinical concern.

How long should these patients remain on prophylactic anticoagulation and who should follow them up?

The vast majority of the trial data pertaining to these patients continued prophylactic anticoagulation for the duration of immobilisation in plaster and until return to baseline mobility. This often constitutes a period of 4-6 weeks. However, with the advent of newer immobilisation strategies and virtual fracture clinics, it is becoming clear that many patients are being encouraged to mobilise early after injury and often return to weightbearing status and full mobility earlier than initially predicted. As such, it is vital that orthopaedic teams have an interest in this issue; decisions to remove a plaster cast and encourage mobilisation may facilitate earlier cessation of thromboprophylaxis. In addition, bleeding problems early in management may adjust the risk/benefit profile.

How do I use SDM in this context?

SDM involves the clinician offering options and describing their risks and benefits, the patient expressing his or her preferences and values, and then both jointly agreeing on a treatment decision. Emergency physicians appear supportive of this approach, and a number of tools have been developed, or are being developed, to support SDM in emergency care. ${ }^{5152}$ RAMs such as the Plymouth rule have been designed to allow potential completion by patients and to guide subsequent informed discussion. However, we are not aware of any published decision tools specifically incorporating SDM relevant to thromboprophylaxis in lower limb immobilisation. Data presented here could be used to support SDM and to develop such a tool.

\section{Cases: outcome}

\section{Case 1}

This patient has both temporary and permanent risk factors for VTE. Her age and BMI are also of concern. She has a Plymouth score of 4 and an L-TRIP(cast) score of 10 and would meet GEMNet criteria for recommendation of thromboprophylaxis. As such, she should be counselled regarding her acutely increased risk of VTE. She should be informed that her absolute risk is likely to be higher than $2 \%$. 
Guidance regarding the clinical signs and symptoms of VTE should be provided in verbal and written form, and measures advised to mitigate risk (such as adequate hydration and mobilisation of the unaffected limb). The first and second authors would offer and prescribe prophylactic dose LMWH or a DOAC, respectively, up to the point of next orthopaedic review. The patient would be counselled on the minor risk of bleeding and informed that any treatment can be revisited at further orthopaedic follow-up, depending on clinical progress. A focal point of contact for immediate concern would be provided.

\section{Case 2}

This patient has temporary but no clear permanent risk factors for VTE. He is also young and the immobilisation method chosen is less restrictive. He has a Plymouth score of 0 and an L-TRIP(cast) score of 3 and would not meet GEMNet criteria for recommendation of thromboprophylaxis. He should still be informed of a potential VTE risk, but this is likely to be an absolute risk lower than $2 \%$.

Guidance regarding the clinical signs and symptoms of VTE should be provided in verbal and written form, and measures advised to mitigate risk (such as adequate hydration and mobilisation of the affected and unaffected limb). The first and second author would not routinely offer prophylactic anticoagulation for this clinical scenario, based on the low VTE risk and the limited application of the available data to non-rigid immobilisation. The patient should be informed that any signs or symptoms of VTE should be disclosed at further orthopaedic follow-up or earlier as required. A point of focal contact for immediate concern should be provided.

\section{SUMMARY}

In patients with temporary lower limb immobilisation after trauma, the absolute risk of symptomatic VTE is low, at approximately $2 \%$. Current evidence suggests that pharmacological prophylaxis can significantly reduce this risk. The benefits of thromboprophylaxis are achieved mainly through reduction of morbidity rather than lives saved. Pharmacological prophylaxis appears to be cost-effective.

Risk assessment can help inform SDM and individually tailor thromboprophylaxis, but there is limited evidence of external validation for any specific method at present. A key aspect of the risk assessment process is the sharing of information; clinicians must inform patients that there is an increased risk of VTE with temporary immobilisation and what the common presenting features are, even if the absolute risk is low.

\section{Twitter Daniel Horner @rcemprof}

Acknowledgements The authors thank all additional members of the core project group for HTA 15/187/06 for input and commentary throughout the work, including Shan Bennet and Robin Pierce-Williams for providing patient and public involvement. The authors also thank Mark Clowes for his assistance with the initial literature searches and article sourcing. We are also indebted to Joanne Hinde for assistance with logistics and administration.

Contributors DH and SG conceived the idea for this review and also acted as co-chief investigators for HTA 15/187/06. With regard to the wider project, AP was responsible for systematic review work; JWS was responsible for the statistical aspects; SD was responsible for the decision modelling and cost-effectiveness work; and TN, BH, KH and JK provided clinical expertise throughout the project. DH and SG were responsible for the drafting of this paper, although all authors provided comments on the drafts and read and approved the final version. DH is the guarantor for the paper.

Funding Much of the work cited in this review was funded by the UK National Institute for Health Research (NIHR) Health Technology Assessment Programme (project number 15/187/06). The views expressed in this review are those of the authors and not necessarily those of the NIHR HTA Programme. Any errors are the responsibility of the authors. The funders had no role in the study design; collection, analysis and interpretation of data; writing of the manuscript; and decision to submit the manuscript for publication.

Competing interests None declared.

Patient consent for publication Not required.

Provenance and peer review Not commissioned; externally peer reviewed.

Open access This is an open access article distributed in accordance with the Creative Commons Attribution Non Commercial (CC BY-NC 4.0) license, which permits others to distribute, remix, adapt, build upon this work non-commercially, and license their derivative works on different terms, provided the original work is properly cited, appropriate credit is given, any changes made indicated, and the use is non-commercial. See: http://creativecommons.org/licenses/by-nc/4.0/.

\section{ORCID iDs}

Daniel Horner http://orcid.org/0000-0002-0400-2017

Steve Goodacre http://orcid.org/0000-0003-0803-8444

Sarah Davis http://orcid.org/0000-0002-6609-4287

\section{REFERENCES}

1 House, Of Cet al. The prevention of venous thromboembolism in hospitalised patients - second report of session 2004-2005. London: The Stationary Office, 2005.

2 Grosse SD, Nelson RE, Nyarko KA, et al. The economic burden of incident venous thromboembolism in the United States: a review of estimated attributable healthcare costs. Thromb Res 2016;137:3-10.

3 ISTH, Steering Cet al. Thrombosis: a major contributor to the global disease burden. J Thromb Haemost 2014;12:1580-90.

4 Bertoletti L, Righini M, Bounameaux H, et al. Acute venous thromboembolism after non-major orthopaedic surgery or post-traumatic limb immobilisation. Thromb Haemost 2011;105:739-41.

5 NICE. Venous thromboembolism in over 16S: reducing the risk of hospital-acquired deep vein thrombosis or pulmonary embolism (NG89), 2018. Available: https://www. nice.org.uk/guidance/ng89/chapter/Recommendations\#terms-used-in-this-guideline [Accessed 11 Jun 2019].

6 Falck-Ytter Y, Francis CW, Johanson NA, et al. Prevention of VTe in orthopedic surgery patients: antithrombotic therapy and prevention of thrombosis, 9th ED: American College of chest physicians evidence-based clinical practice guidelines. Chest 2012;141:e278S-325.

7 Smith J, Keating L, Flowerdew L, et al. An emergency medicine research priority setting partnership to establish the top 10 research priorities in emergency medicine. Emerg Med J 2017;34:454-6.

8 Chen L, Soares D. Fatal pulmonary embolism following ankle fracture in a 17-year-old girl. J Bone Joint Surg Br 2006;88-B:400-1.

9 Irish, Times. Coroner to highlight blood clot risks following sudden death of CO Tyrone church Minister Irishnews.com, 2019. Available: https://www.irishnews.com/news/ 2018/08/08/news/coroner-to-highlight-blood-clot-risks-following-sudden-death-ofco-tyrone-church-minister-1402184/ [Accessed 11 Jun 2019].

10 Maclean R, Roberts C. Personal communication. personal email regarding the use of DOAC medications as thromboprophylaxis for patients in lower limb plaster, as well as description of recent section 28 recommendation by coroner to avoid future deaths that risk assessment and thromboprophylaxis for this indication become mandatory 2017.

11 Zee AAG, van Lieshout $K$, van der Heide $M$, et al. Low molecular weight heparin for prevention of venous thromboembolism in patients with lower-limb immobilization. Cochrane Database Syst Rev 2017;376.

12 Horner D, Hogg K, Body R. Should we be looking for and treating isolated calf vein thrombosis? Emerg Med J 2016;33:431-7.

13 Horner D, Hogg K, Body R, et al. The anticoagulation of calf thrombosis (act) project: results from the randomized controlled external pilot trial. Chest 2014;146:1468-77.

14 Jones T, Horner D. Bet 2: striking the right balance: anticoagulation and isolated distal deep vein thrombosis. Emerg Med J 2017;34:334-6.

15 Nemeth B, Cannegieter SC. Venous thrombosis following lower-leg cast immobilization and knee arthroscopy: from a population-based approach to individualized therapy. Thromb Res 2019;174:62-75.

16 Bruntink MM, Groutars YME, Schipper IB, et al. Nadroparin or fondaparinux versus no thromboprophylaxis in patients immobilised in a below-knee plaster cast (protect): a randomised controlled trial. Injury 2017;48:936-40.

17 Jørgensen PS, Warming T, Hansen K, et al. Low molecular weight heparin (Innohep) as thromboprophylaxis in outpatients with a plaster cast. Thromb Res 2002;105:477-80.

18 Kock H-J, Schmit-Neuerburg KP, Hanke J, et al. Thromboprophylaxis with lowmolecular-weight heparin in outpatients with plaster-cast immobilisation of the leg. The Lancet 1995;346:459-61.

19 Lapidus LJ, Ponzer S, Elvin A, et al. Prolonged thromboprophylaxis with dalteparin during immobilization after ankle fracture surgery: a randomized placebo-controlled, double-blind study. Acta Orthop 2007;78:528-35. 
20 Lassen MR, Borris LC, Nakov RL. Use of the low-molecular-weight heparin reviparin to prevent deep-vein thrombosis after leg injury requiring immobilization. $N$ Engl J Med 2002;347:726-30.

21 van Adrichem RA, Nemeth B, Algra A, et al. Thromboprophylaxis after knee arthroscopy and Lower-Leg casting. N Engl J Med 2017;376:515-25.

22 Horner D, Stevens J, Pandor A, et al. Pharmacological thromboprophylaxis to prevent venous thromboembolism in patients with temporary lower limb immobilization after injury: systematic review and network meta-analysis. J Thromb Haemost 2019.

23 Pandor A, Horner D, Davis S, et al. Pharmacological thromboprophylaxis for lower limb immobilisation after injury: systematic review and economic evaluation. Health Technology Assessment. 2018

24 Gehling H, Giannadakis K, Lefering R, et al. [Prospective randomized pilot study of ambulatory prevention of thromboembolism. 2 times $500 \mathrm{mg}$ aspirin (ASS) vs. clivarin 1750 (NMH)]. Unfallchirurg 1998;101:42-9.

25 Goel D, Buckley R, deVries G, et al. Prophylaxis of deep-vein thrombosis in fractures below the knee: a prospective randomised controlled trial. The Journal of Bone and Joint Surgery 2009;91.

26 Kujath P, Spannagel U, Habscheid W. Incidence and prophylaxis of deep venous thrombosis in outpatients with injury of the lower limb. Haemostasis 1993;23 Suppl $1: 20-6$.

27 Lapidus LJ, Rosfors S, Ponzer S, et al. Prolonged thromboprophylaxis with dalteparin after surgical treatment of Achilles tendon rupture: a randomized, placebo-controlled study. J Orthop Trauma 2007;21:52-7.

28 Samama CM, Lecoules N, Kierzek G, et al. Comparison of fondaparinux with low-molecular-weight heparin for venous thromboembolism prevention in patients requiring rigid or semi-rigid immobilization for isolated non-surgical below-knee injury. Annales Francaises de Medecine d'Urgence 2014;4:153-66.

29 Selby R, Geerts WH, Kreder HJ, et al. A double-blind, randomized controlled trial of the prevention of clinically important venous thromboembolism after isolated lower leg fractures. J Orthop Trauma 2015;29:224-30.

30 Zheng X, Li D-Y, Wangyang Y, et al. Effect of chemical thromboprophylaxis on the rate of venous thromboembolism after treatment of foot and ankle fractures. Foot Ankle Int 2016:37:1218-24.

31 Kaatz S, Ahmad D, Spyropoulos AC, et al. Definition of clinically relevant non-major bleeding in studies of anticoagulants in atrial fibrillation and venous thromboembolic disease in non-surgical patients: communication from the SSC of the ISTH. J Thromb Haemost 2015;13:2119-26.

32 Schulman S, Angeras U, Bergqvist D, et al. Definition of major bleeding in clinical investigations of antihemostatic medicinal products in surgical patients. J Thromb Haemost 2010;8:202-4.

33 Schulman S, Kearon C, et al, Subcommittee on Control of Anticoagulation of the Scientific and Standardization Committee of the International Society on Thrombosis and Haemostasis. Definition of major bleeding in clinical investigations of antihemostatic medicinal products in non-surgical patients. J Thromb Haemost 2005;3:692-4.

34 Davis S, Goodacre S, Pandor A, et al. Decision-analysis modelling of the effects of thromboprophylaxis for people with lower limb immobilisation for injury. Br J Haematol 2019.
35 Kahn SR, Ginsberg JS. Relationship between deep venous thrombosis and the postthrombotic syndrome. Arch Intern Med 2004;164:17-26.

36 Nemeth B, Adrichem RAvan, Hylckama Vlieg Avan, et al. Venous Thrombosis Risk after Cast Immobilization of the Lower Extremity: Derivation and Validation of a Clinical Prediction Score, L-TRiP(cast), in Three Population-Based Case-Control Studies. PLoS Med 2015;12:e1001899-e99.

37 Watson U, Hickey BA, Jones HM, et al. A critical evaluation of venous thromboembolism risk assessment models used in patients with lower limb cast immobilisation. Foot and Ankle Surgery 2016;22:191-5.

38 Caprini JA, Arcelus JI, Reyna J. Effective risk stratification of surgical and nonsurgical patients for venous thromboembolic disease. Semin Hematol 2001;38:12-19.

39 Horner D, Pandor A, Goodacre S, et al. Individual risk factors predictive of venous thromboembolism in patients with temporary lower limb immobilization due to injury: a systematic review. J Thromb Haemost 2019;17:329-44.

40 Nemeth B, van Adrichem R, Nelissen R, et al. Individualized thromboprophylaxis in patients with Lower-Leg cast Immobilization-A validation and subgroup analysis in the POT-CAST trial. Thromb Haemost 2019:119:1508-16.

41 Saragas NP, Ferrao PNF, Jacobson BF, et al. The benefit of pharmacological venous thromboprophylaxis in foot and ankle surgery. S Afr Med J 2017;107:327-30.

42 Roberts C, Horner D, Coleman G, et al. Guidelines in emergency medicine network (GEMNet): guideline for the use of thromboprophylaxis in ambulatory trauma patients requiring temporary limb immobilisation. Emerg Med J 2013;30:968-82.

43 Nokes TJCaK J. Venous thromboembolism risk assessment V2. plymouth (Derriford Hospital) 2010

44 Giannadakis K, Gehling H, Sitter H, et al. Is medicamentous thrombosis prophylaxis necessary in conservative outpatient therapy with lower limb injuries? Unfallchirurg 2000;103:475-8

45 Eingartner $C$, Hontzsch D, Lang E, et al. Individualized prophylaxis for thromboembolism in outpatients - A practical way out between 'ever' and never'? Aktuelle Traumatologie 1995;25:1-5.

46 Haque S, Bishnoi A, Khairandish H, et al. Thromboprophylaxis in ambulatory trauma patients with foot and ankle fractures: prospective study using a risk scoring system. Foot Ankle Spec 2016:9:388-93.

47 Douillet D, Nemeth B, Penaloza A, et al. Venous thromboembolism risk stratification for patients with lower limb trauma and cast or brace immobilization. PLoS One 2019;14:e0217748

48 Haque S, Davies MB. Oral thromboprophylaxis in patients with ankle fractures immobilized in a below the knee cast. Foot and Ankle Surgery 2015;21:266-8.

49 Keenan J, Hall MJ, Nokes TJC. A practical VTe risk assessment score tool for patients treated with lower limb cast immobilization. Injury Extra 2009;40:199-200.

50 Baglin T, Barrowcliffe TW, Cohen A, et al. Guidelines on the use and monitoring of heparin. Br J Haematol 2006;133:19-34.

51 Probst MA, Kanzaria HK, Frosch DL, et al. Perceived appropriateness of shared decision-making in the emergency department: a survey study. Acad Emerg Med 2016;23:375-81

52 Melnick ER, Probst MA, Schoenfeld E, et al. Development and testing of shared decision making interventions for use in emergency care: a research agenda. Acad Emerg Med 2016;23:1346-53. 